\title{
The Development of China's Hotel Industry and the Necessity of Implementing Information Technology
}

\author{
Manping Weng, Xiaofang Wang* \\ Liming Vocational University, Quanzhou, Fujian, China \\ Email: weng28911985@163.com \\ *Corresponding author: Xiaofang Wang
}

Keywords: modern hotel industry; informatization; electronic commerce

\begin{abstract}
Since the reform and opening-up, China's modern hotel industry has developed to a large extent, at the same time, it is also facing many challenges. Therefore, with the process of marketization, consumption, hi-tech, ecologicalization and individualization, the implementation of information is the main trend of modern hotel industry in our country. This paper firstly analyzes the development of modern hotel industry in China and the challenges it faces; secondly, describes that the implementation of information technology is the main trend of modern hotel management; finally, puts forward the specific application of electronic commerce in modern hotel industry.
\end{abstract}

\section{Introduction}

From the management of Hospitality Management to the operation management of enterprise units, from experience management to scientific management, the star rating is introduced to enter the new stage of international modern management; the establishment of hotel management companies, hotel to specialization and collectivization, and management tend to legalization.

\subsection{The general situation of China's hotel industry}

The industrialization scale of hotel is huge, and the investment amount of the hotel is huge. When the hotel enters the buyer's market, the enterprise will enter the era of meager profit era. The supply and demand is relatively loose, the competition in the hotel market is intense, and the group business is developing, so the hotel industry is facing new challenges.

These challenges are mainly reflected in(1)the huge impact of the wave of economic globalization on China's hospitality market.Whether it can develop itself as soon as possible, and form an international competitiveness is a severe challenge faced by China's hotel industry .(2) the challenge of joining the World Trade Organization(WTO). This is our country's hotel industry must be well prepared to meet the impact of international capital , the technological impact, the cultural shock, the impact of the tourists , the impact of the talents and the impact of the benefit of the hotel industry in China. (3)The challenge of high technology development.(4)the challenge of domestic economic situation transformation; at present, China’s economic is in two phases: firstly, the key period of system reform; secondly ,the key period of economic development. (5) the challenge of customer demand and change to the restructuring of the hotel product structure and the change of service mode.

\subsection{The future trend of China's hotel}

Firstly, the concept of hotel management is deepened, the concept of respect for and care for the consumer are gradually deepened, and the structure of the enterprise is flat; pay attention to the brand and assets management, etc; secondly , the appreciation of hotel culture connotation; thirdly, new technology is widely used, such as software application of enterprise management and network management,etc; fourthly, hotel group development and brand management; fifthly, hotel producers diversification, characteristics and personalization; sixth, the market of highly differentiated and diversified; seventh, propose green consumption and green management; finally, hotel human 
resources development andemployment system socialization.

\section{The Wide Application as the Main Trend of Hotel Management Modernization.}

With the continuous improvement of performance of computer and the declining price, computers have been widely applied in various aspects of hospitality, tourism, catering and service industries. The computerizes hospitality, tourism, catering and service system has become an essential infrastructure and technology supporting environment for these enterprises, just like a modern hotel successful operation is inseparable from the functional, beautiful and comfortable building, a well managed executive, a fully equipped sophisticated hotel and catering equipment, it can also be inseparable from computerized enterprise information system. The main goal of hotel management information system (including software ) is to support hotel businesses, reduce labor intensity of the business processors and assist senior leaders in the decision making of the top leaders of the enterprises and improve the efficiency of enterprises, so that the hotel can get a better social and economic benefit with less investment, such as financial software, personnel management software, hotel management system, catering management system belong to the scope of hotel management information system. Hotel information system should not only track the management information generated by the flow of people, money and logistics, but also improve the efficiency of the whole business operation, and support the whole humanities, public relations and scientific research activities centered on the customer consumption information records. In a board sense, the hotel management information system is a specific application of the management information system (MIS) in a hotel environment. So it must have the following features that are common to other MIS systems.

(1) Take the database as the core, take the network as the technical support for the environment of turning, the computer system has a certain scale.

(2) Taking business as the main line and improving work quality and efficiency and auxiliary decision-making as the main purpose, we can improve the level of comprehensive management, reflect the overall picture of enterprises, and get more and better information systems for social and economic benefits.

(3) In the internal system it is divided into several subsystem according to certain principles(may also as layer system in this system),each subsystem, mutual interface between subsystems, can effectively exchange information, realize the sharing of information resource.

(4) Processed objects have both structured data and semi structured or unstructured data. Some data and structures are more affected by artificial intervention and social factors, that is, static and dynamic.

(5) The development is difficult, the technology is complex and the cycle is long.

(6) Perfect management, supervision and operation of security system and the corresponding regulations and the security information system

\section{The Hotel Information System Introduces Many Unique Characteristics of MIS System.}

These characteristics often bring more difficulty and complexity to the design and implementation of hotel information system, we can sum up as follows:

(1) In many cases, it requires rapid speed of the response and online transaction processing capability. At present, the hotel information system of higher stars( such as some five star hotels) can be said to be no less than any bank window business system, ticket booking and sales system.

(2) Hotel information is complex. Guest information is expressed in a variety of data types, which requires not only text and data, but also graphics, charts, and so on.

(3) The security requirements of the information are high. The records of guests, especially for very important guests, especially for very quests, such as president of a state, a president of a state enterprise, etc, have strict confidential requirements for personnel, finance and even personal consumption.

(4) Data cover is large. It is a common that the information of hundreds of thousands of guests in 
a large comprehensive hotel.

(5) Lack of hotel information processing standards. At present, China's food industry also lacks the standard of hotel information expression, hotel management model and information system model.

(6) The overall objective, system, organization, management method and information flow mode of hotel are difficult for us to analyze, design and implement a hotel information system.

(7) High level of information sharing needs. The sharing design of information, the speed and security of information transmission, and the reliability of the network must be guaranteed in the hotel's information system.

\section{The Realization of the Information System in the Hotel Should Have its Social Functional Requirements.}

The database management system should have a large scale and high efficiency support and have strong online transaction processing ( on line transaction processing, OLTP) support ability; typical 24 hours uninterrupted system requirements, absolutely safe and reliable; friendly man-machine interface, easy to use, tailoring property and elasticity. To adapt to the needs of different development plans of the hotel; openness and portability, adapt to different hardware and software platform; modular structure, augmentability.

At present, the use of e-commerce in hotels is more and more. The state information center, China information Corporation announced on September 25, 1998 that the" guoxin commercial alliance of Chinese hotel reservation network" officially began operations. This is the first domestic example based on internet and the successful application of the advanced e-business model to the tourism service industry. The reservation is approved by the State Development Planning Commission, the state information Corporation, which is responsible for the operation of a business travel services mainly for travel booking service network and provides overseas customers with a number of comprehensive travel booking services, including hotel reservations, ticket reservations, and tourist routes. At present, the network has opened the hotel reservation service, through which the customers can enjoy the 4-7discount, it is reported that "the guoxin commercial alliance of Chinese hotel reservation network "has joined more than 300 hotels, located in the country more than 50 large and medium-sized city. The reservation network is a member system, and the membership card is issued for each customer. However, there are more than 5700 foreign-related hotels and more than 3000 star rated hotels. Most of them do not have their own websites. Most of them still cannot provide internet services for business guests. In 1998, China has jumped to the world's ten largest tourist country in the world, earning more than 10 billion dollars in tourism. However, due to the imperfect settlement means, 2 billion of them still remain abroad. From the application of electronic commerce in China's hotel industry, IT technology mainly scheduled service and hotel introduction etc. But it is just the only implementation of B to C (business to customer ) the primary form of the pattern. In addition, e-commerce and B2B(business to business model) in each model, all have a very wide range of applications and prospects. With the improvement of the infrastructure of e-commerce in China, the supporting environment is becoming more and more standardized and improved. With the increase of geometric progression, internet users' consumption attitudes and behaviors will change dramatically, and the acceptance of e-commerce will continue to improve. The hotel industry e-commerce save strength to start out, the domestic relevant departments have been more and more attention to the hotel industry in internet and e-commerce applications, with the rapid growth of world economy and human exchanges become more frequently, the tourism industry has entered the world's largest industry. As one of the pillar industries in tourism industry the hotel industry should seize the opportunity to actively explore the field of electronic commerce.

\section{Acknowledgement}

Foundation Project: Fujian Province Educational Science "Thirteenth Five-Year Plan" 2017 
cross-strait Vocational Education Special Research Project

\section{References}

[1] The Evolution and Development Mode of Hotel Informatization[J].Diao Zhibo. Journal of Beijing second Foreign language University.2010,01,56-62.

[2] Innovation, change has become the main theme of hotel industry development [N].Chen Jing. Chinese Travel News.2016, A01, 112-119.

[3] The "Internet+" has become a new driving force for hotel industry transformation [N].Jiang Yongxia. Chinese Business Daily. 2015, P01, 123-128.

[4] A study on the relationship between the Development of Hotel Industry and Economic growth in China [J].Deng Aimin, Zhang Ruolin. Journal of Shandong University of Finance and Economics, 2017, 03, 451-455.

[5] Comparative Analysis on the rationality of the Development of Regional Star Hotel Industry-A case study of 16 popular tourist provinces and cities in China [J].Zhang Youyin, Gu Jing, Ma Yaofeng, Li Xin. Soft Science. 2013, 35, 226-229.

[6] Discussion on the problems and Countermeasures of Intelligent Hotel Construction in China [J].Zhong Yan, Gao Jianfei. Commercial economy Research. 2017, 18, 18-23.

[7] Research on Informatization Construction of domestic Hotels Group [J].Zhong Yan, Gao Jianfei. Business era. 2013, 35, 112-116. 